\title{
Smartphone Use Patterns of Smartphone-dependent Children
}

\author{
Jeong Hye Park \\ Assistant Professor, Department of Nursing, Gyeongnam National University of Science and Technology, Jinju, Korea
}

Purpose: The purpose of this study was to identify the smartphone use patterns of smartphone-dependent children. Methods: The study design was a cross-sectional descriptive study. The data were derived from the 2017 survey on smartphone overdependence conducted by the Ministry of Science and ICT and the National Information Society Agency. The study sample was 595 elementary school students identified as being smartphone-dependent. The data were analyzed by frequency, percentage, mean, standard deviation, the independent t-test, the $x^{2}$ test, the Pearson correlation coefficient, and multiple regression analysis. Results: The frequency of smartphone use was the factor strongly associated with more severe smartphone dependence in participants. Games were the most commonly used application type among participants, regardless of their degree of dependence. More severe smartphone dependence was associated with greater use of applications such as learning and television/video. Conclusion: As smartphone dependence becomes more severe, children tend to use their smartphones more frequently and to use applications that involve solitary play for the purposes of entertainment and pleasure. The findings suggest that the parents should attentively monitor their children's smartphone use patterns and provide consistent discipline in a way that ensures appropriate smartphone use.

Key words: Child; Smartphone; Cell phone

\section{Corresponding author Jeong Hye Park \\ https://orcid.org/0000-0002-7011-5888}

Department of Nursing, Gyeongnam National University of Science and Technology, 33 Dongin-ro, Jinju 52725, Korea

TEL +82-55-751-3614 FAX +82-55-751-3659

E-MAIL masternur@naver.com

Received Sep 19, 2019 Revised Nov 18, 2019 Accepted Dec 31, 2019
(9) This is an Open Access article distributed under the terms of the Creative Commons Attribution NonCommercial License (http://creativecommons.org/licenses/by-nc/4.0/) which permits unrestricted noncommercial use, distribution, and reproduction in any medium, provided the original work is properly cited.

\section{INTRODUCTION}

In $2018,89.5 \%$ of the South Korean population aged 3 and over used smartphones [1]. The spread of smartphone use is causing a variety of issues, one of which is smartphone dependence. Smartphone dependence refers to a condition characterized by smartphone overuse, a dysfunctional ability to control one's desires for smartphone use, or other experiences of adverse effects arising from smartphone use [2]. In South Korea, smartphone dependence has been defined as a condition involving a failure of self-control over smartphone use, increased salience of smartphone use, and serious consequences due to smartphone overuse [1]. Salience refers to a pattern in which smartphone use becomes more discernable and prevalent than other daily activities in one's personal life; failure of self-control means that the ability of a user to control his or her smartphone use is lower than the user's subjective intent to do so; and serious consequences refer to a tendency for the user to continue smartphone overuse despite experiencing undesired physical, psychological, and social effects of smartphone use [1]. The rate of smartphone dependence in South Korea is steadily increasing, from $8.4 \%$ in 2011 to $19.1 \%$ in 2018 [1]. In statistics from 2018, middle school students showed the highest dependency rate $(34.0 \%)$, followed by 
high school students $(28.3 \%)$ and elementary school students $(22.8 \%)$. At a glance, it may seem that the dependency rate for elementary school students is lower than that of middle or high school students. However, while the dependency rate for secondary school students decreased slightly from 2017, by $0.3 \sim 0.4 \%$, it increased by $0.8 \%$ for elementary school students [1] and the increase in smartphone dependence over the last $3 \sim 4$ years has been the most significant in this age group $[1,3]$.

Elementary school students are in the school-age phase of childhood development, during which children undergo rapid growth and cultivation of various aspects of the human experience. During this phase, children develop sociality, along with the active interactions with peers in the same age group [4]. They learn a sense of achievement and diligence by acquiring and utilizing the behavioral patterns required by society [4]. All these experiences may have a profound impact on the formation of positive self-concept and self-esteem [4]. However, smartphone overuse may inflict myriad issues on children's healthy growth and development, including reduced physical activity due to increased sedentary time [5], deterioration of vision, reduced quality of sleep, decreased participation in social activities, and increased risk for depression or anxiety. Moreover, the quick and easy access and transfer of information may be detrimental for children's cognitive development by inducing a decrease in critical thinking and concentration [6,7]. Therefore, it is essential to provide children appropriate guidance and education about healthy smartphone habits.

Previous studies have reported some factors associated with smartphone dependence, of which smartphone use patterns associated with smartphone dependence are particularly important. These include the frequent use of smartphones and excessive or increased use of games, social networking services (SNS), and messengers [8-10]. A study reported that smartphone dependence tended to increase as the use of video and music increased among children [11]. We could therefore identify the detrimental characteristics of certain patterns of smartphone use and use them in interventions to prevent and treat smartphone dependence [8-10]. However, only a few studies have reported smartphone use patterns among elementary school students $[8,12,13]$, and it is difficult to apply those findings to smartphone-dependent elementary school students.

Therefore the purpose of this study was to identify the comprehensive use patterns associated with smartphone dependence among smartphone-dependent elementary school students, considering the high rate of dependence and the impact of smartphone dependence on children's growth and development.

\section{METHODS}

\section{Participants}

The participants of this study were drawn from a pool of 2,554 current elementary school students who used smartphones. Of these students, 595 students (23.3\%) identified as being smartphone dependent were selected. A smartphone user was defined a person who accessed the internet at least once within the last month using a smartphone, a category that was defined to include tablets [3].

\section{Measurements}

\section{1) Smartphone dependence scale}

A scale for smartphone dependence was developed by the Ministry of Science and ICT and the National Information Society Agency in 2015 and modified in 2016. The validity of this scale has been repeatedly verified through annual nationwide surveys [1]. This scale is composed of three subscales (salience, failure of self-control, and serious consequences) and categorizes the degree of smartphone dependence into potential-risk and high-risk use. The users in potential-risk group have reduced self-control over smartphone use, and issues in daily activities and interpersonal relations begin to surface. Those in high-risk group have almost fully lost selfdiscipline over smartphone use, as shown by their tendency to spend a significant amount of time during the day using a smartphone, and suffer from severe issues in interpersonal relationships, daily routines, and physical health as a result of their smartphone use habits [14]. Moreover, this scale contains four distinct questionnaires-for children, adolescents, adults, and seniors-to ensure an accurate determination depending on the participants' age [14]. The versions of the scale used for this study were those for children and adolescents, which are aimed for participants aged 3 9 and 10 19, respectively. The participants of this study who were 9 years of age or younger responded to the questions on the children's version, while those aged 10 or older responded to the questions on the adolescents' version.

The respondents of the children's questionnaires were the children's primary caregivers, based on their observations of the children's behaviors and attitudes. The questionnaire contains three questions in each subscale (nine questions overall) with a 4-point scale (strongly disagree, 1 point; strongly agree, 4 points). The threshold for dependence is 24 points or more out of 36 points, with higher scores indicating more severe dependence. Participants who receive a score between 24 and 27 points are considered to be potential-risk users, while those who receive 28 points or more are considered to be high-risk 
users. When the scale was modified, the overall reliability of the children's scale was assessed using Cronbach's $\alpha$, with a value of .75 [14]. Cronbach's $\alpha$ was .76 in this study. The adolescents' scale contains 10 questions in three sections: three on failure of self-control, three on salience, and four on serious consequences. Each question is scored on a 4-point scale (strongly disagree, 1 point; strongly agree, 4 points). The threshold for dependence is 23 points out of 40 , with higher scores indicating more severe dependence on smartphone use. Participants who receive $23 \sim 30$ points are considered to be potential-risk users, while those who receive 31 points or higher are considered to be high-risk users. The overall reliability of the adolescents' scale when it was modified was assessed using Cronbach's $\alpha$, with a score of 84 [14]. Cronbach's $\alpha$ was .81 in this study.

\section{2) Smartphone use patterns}

Smartphone use patterns included the following variables: the duration and the frequency of smartphone use, the types of used applications, and the degree of use of each application type. The duration and the frequency of smartphone were calculated as the average values of these parameters per day during the last 1 month. Applications were classified by type as learning, news, web searching, web surfing, games, television /videos, music, webtoons, messengers, and SNS $[9,15]$. The webtoon category included web novels, and messengers included text messages and instant messengers. The degree of use of each application type was measured on a 7-point Likert scale from not at all (0) to very frequently (7)

\section{Data Collection}

The data for this study were derived from the 2017 survey on smartphone overdependence conducted by the Ministry of Science and ICT and the National Information Society Agency. In this survey, data were collected as follows [3]: The target population was smartphone users between the age of 3 and 69 , living in households nationwide. Samples were obtained through stratified systematic sampling. The survey was conducted among all smartphone users in 10,000 households nationwide. Trained surveyors collected data through house visits and interviews from September 2017 to November 2017. The collected data were initially verified by regional supervisors assigned to each survey district. Then, at least 30\% of the collected responses were randomly selected and their content was further verified with respondents via phone calls as a secondary verification procedure. As a tertiary verification procedure, a statistical expert confirmed the scope of the responses, the branching of survey questions, and the consistency of responses among the questions. If any error was iden- tified, an additional or repeated survey was conducted to ensure the validity of the data.

The data were requested and obtained according to the standard procedures presented by the Ministry of Science and ICT and the National Information Society Agency [16]. The data were provided through the author's e-mail after the request was approved.

\section{Ethical Considerations}

The data used for this study are general statistics approved for usage pursuant to Article 14, Paragraph 3 of the Framework Act on National Informatization, and Article 8, Paragraph 1 of the Statistics Act. When an institution releases statistical data, the personal identifying information of the respondents is codified with serial numbers or removed to prevent identification of the participants. In order to utilize these data, the Institutional Review Board of the Korea National Instituter for Bioethics Policy granted approval for human studies before the study commenced (P01-201905-21-011).

\section{Data Analysis}

The data for this study were analyzed with SPSS version 23.0 (IBM Corp., Armonk, NY, USA).

The frequency, percentage, mean, and standard deviation were used to describe participants' characteristics and smartphone use patterns. The $x^{2}$ test and the independent-sample t-test were used to analyze differences in smartphone dependence according to the independent variables. Correlations among smartphone dependence and smartphone use patterns were evaluated using Pearson correlation coefficients. Weighted multiple regression analysis (the enter method) was used to investigate the factors associated with more severe smartphone dependence.

\section{RESULTS}

\section{Differences in Smartphone Dependence According to Smartphone Use Patterns}

Of the participants, $17.3 \%(\mathrm{n}=103)$ were in the high-risk group. The differences in smartphone dependence according to smartphone use patterns were presented in Table 1. The users in potential-risk group used smartphones significantly less than those in high risk group. The mean duration of smartphone use per day was $2.03 \pm 1.61$ hours in the potential-risk group, while it was $2.81 \pm 1.61$ hours in the high-risk group $(\mathrm{t}=4.50, p<.001)$. The frequency of smartphone use per day was $20.79 \pm 28.40$ times in the potential-risk group, and 
Table 1. Differences in Smartphone Dependence According to Demographic Characteristics and Smartphone Use Patterns ( $N=595)$

\begin{tabular}{|c|c|c|c|c|}
\hline \multirow{3}{*}{ Variables } & \multirow{3}{*}{ Categories } & \multicolumn{2}{|c|}{ Smartphone dependence } & \multirow{3}{*}{$x^{2}$ or $\mathrm{t}(p)$} \\
\hline & & \multirow{2}{*}{$\begin{array}{c}\text { Potential-risk group }(\mathrm{n}=492) \\
\mathrm{n} \text { (weight } \%) \text { or } \mathrm{M} \pm \mathrm{SD}\end{array}$} & \multirow{2}{*}{$\begin{array}{c}\text { High-risk group ( } \mathrm{n}=103 \text { ) } \\
\mathrm{n} \text { (weight } \% \text { ) or } \mathrm{M} \pm \mathrm{SD}\end{array}$} & \\
\hline & & & & \\
\hline \multirow[t]{2}{*}{ Sex } & Male & $244(84.1)$ & $46(15.9)$ & \multirow[t]{2}{*}{$0.83(.387)$} \\
\hline & Femald & $248(81.3)$ & $57(18.7)$ & \\
\hline \multirow[t]{2}{*}{ Age (year) } & Under 9 & $229(79.0)$ & $61(21.0)$ & \multirow[t]{2}{*}{$5.48(.023)$} \\
\hline & Over 10 & $263(86.2)$ & $42(13.8)$ & \\
\hline \multicolumn{2}{|c|}{ Duration of smartphone use (hours per day) } & $2.03 \pm 1.61$ & $2.81 \pm 1.61$ & $4.50(<.001)$ \\
\hline \multicolumn{2}{|c|}{ Frequency of smartphone use (times per day) } & $20.79 \pm 28.40$ & $44.01 \pm 53.25$ & $4.30(<.001)$ \\
\hline \multirow[t]{10}{*}{ Degree of use } & Learning & $2.96 \pm 2.25$ & $4.04 \pm 2.28$ & $4.43(<.001)$ \\
\hline & News & $1.14 \pm 1.91$ & $1.19 \pm 2.02$ & $0.24(.811)$ \\
\hline & Searching for information & $1.07 \pm 1.78$ & $1.17 \pm 1.81$ & $0.50(.620)$ \\
\hline & Web surfing & $2.21 \pm 2.24$ & $1.45 \pm 2.15$ & $3.25(.001)$ \\
\hline & Games & $4.68 \pm 1.65$ & $5.40 \pm 1.40$ & $4.10(<.001)$ \\
\hline & TV/video & $3.01 \pm 2.44$ & $4.29 \pm 2.05$ & $5.56(<.001)$ \\
\hline & Music & $2.92 \pm 2.43$ & $3.17 \pm 2.52$ & $0.95(.342)$ \\
\hline & Webtoons & $1.39 \pm 2.16$ & $2.09 \pm 2.49$ & $2.62(.010)$ \\
\hline & Messengers & $4.28 \pm 2.22$ & $3.77 \pm 2.76$ & $1.77(.078)$ \\
\hline & SNS & $2.49 \pm 2.48$ & $1.91 \pm 2.49$ & $2.15(.032)$ \\
\hline
\end{tabular}

TV=Television; SNS=Social networking services.

$44.01 \pm 53.25$ times in the high-risk group $(\mathrm{t}=4.30, p<.001)$. The most-used types of application were games (4.68 \pm 1.65 points) and messengers ( $4.28 \pm 2.22$ points) in the potential-risk group, and games (5.40 \pm 1.40 points), TV/video (4.29 \pm 2.05 points), and learning applications $(4.04 \pm 2.28$ points) in the high-risk group. The largest difference in the degree of use of various application types between the two groups was found for $\mathrm{TV} /$ video $(\mathrm{t}=5.56, p<.001)$ and learning applications $(\mathrm{t}=4.43$, $p<.001)$.

\section{Correlations among Smartphone Dependence and Smartphone Use Patterns}

The correlations among smartphone dependence and smartphone use patterns were presented in Table 2. The use patterns that showed significant correlations with smartphone dependence were frequency of smartphone use $(\mathrm{r}=.29, p<$ $.001)$ and webtoons $(\mathrm{r}=.26, p<.001)$, TV/video $(\mathrm{r}=.23, p<.001)$, and learning applications $(\mathrm{r}=.20, p<.001)$.

\section{Smartphone Use Patterns Associated with More Severe Smartphone Dependence}

Multiple regression analysis was used to identify the smartphone use patterns associated with more severe smartphone dependence. The goodness-of-fit test of the regression model indicated that it was appropriate for testing, as the regression equation was useful for explaining the dependent variable
$(\mathrm{F}=9.76, p<.001)$ and showed minimal issues of autocorrelation and multicollinearity, with a Durbin-Watson value of 1.38, a spatial lag of .74 .91, and a variance inflation factor of 1.10 1.61. The $R^{2}$ value of the independent variables for the dependent variable was $14.9 \%$. The results of the regression analysis, adjusted for age group and sex, are presented in Table 3. Smartphone use patterns associated with more severe smartphone dependence were frequent use of smartphones $(\beta=.21, p<.001)$ and higher use of learning applications $(\beta=$ $.24, p<.001)$ and TV/videos $(\beta=.10, p<.001)$.

\section{DISCUSSION}

This study identified the characteristic smartphone use patterns of elementary school students with smartphone dependence, a population about which little is known. Games were the most used application type in both the potential- and high-risk groups. As dependence became more severe, participants' smartphone use became more frequent, and they started to use applications that involve solitary play for pleasure, such as learning applications and TV/videos.

The frequent use of smartphones significantly increased the severity of smartphone dependence among smartphone-dependent elementary school students. The mean frequency of smartphone use in the high-risk group was 44.01 times a day, which was twice that of the potential-risk group (20.79 times a day). In contrast, the duration of smartphone use did not significantly increase the severity of smartphone dependence. 
Table 2. Correlations among Smartphone Dependence, Demographic Characteristics, and Smartphone Use Patterns

$(N=595)$

\begin{tabular}{|c|c|c|c|c|c|c|c|c|c|c|c|c|c|c|c|}
\hline \multirow{2}{*}{\multicolumn{2}{|c|}{ Variables and categories }} & A & B & $\mathrm{C}$ & $\mathrm{D}$ & E & $\mathrm{F}$ & G & $\mathrm{H}$ & $\mathrm{I}$ & $\mathrm{J}$ & $\mathrm{K}$ & $\mathrm{L}$ & $\mathrm{M}$ & $\mathrm{N}$ \\
\hline & & $\mathrm{r}(p)$ & $\mathrm{r}(p)$ & $\mathrm{r}(p)$ & $\mathrm{r}(p)$ & $\mathrm{r}(p)$ & $\mathrm{r}(p)$ & $\mathrm{r}(p)$ & $\mathrm{r}(p)$ & $r(p)$ & $\mathrm{r}(p)$ & $\mathrm{r}(p)$ & $r(p)$ & $\mathrm{r}(p)$ & $\mathrm{r}(p)$ \\
\hline \multicolumn{2}{|c|}{$\begin{array}{l}\text { Smartphone } \\
\text { dependence (A) }\end{array}$} & 1 & & & & & & & & & & & & & \\
\hline \multicolumn{2}{|l|}{ Age (B) } & $\begin{array}{c}.07 \\
(.107)\end{array}$ & 1 & & & & & & & & & & & & \\
\hline \multicolumn{2}{|c|}{$\begin{array}{l}\text { Duration of smartphone } \\
\text { use }(C)\end{array}$} & $\begin{array}{c}.17 \\
(<.001)\end{array}$ & $\begin{array}{c}.29 \\
(<.001)\end{array}$ & 1 & & & & & & & & & & & \\
\hline \multicolumn{2}{|c|}{$\begin{array}{l}\text { Frequency of smartphone } \\
\text { use (D) }\end{array}$} & $\begin{array}{c}.29 \\
(<.001)\end{array}$ & $\begin{array}{c}.23 \\
(<.001)\end{array}$ & $\begin{array}{c}.35 \\
(<.001)\end{array}$ & 1 & & & & & & & & & & \\
\hline \multirow[t]{10}{*}{$\begin{array}{l}\text { Degree } \\
\text { of use }\end{array}$} & Learning (E) & $\begin{array}{c}.20 \\
(<.001)\end{array}$ & $\begin{array}{c}-.09 \\
(.030)\end{array}$ & $\begin{array}{l}-.10 \\
(.014)\end{array}$ & $\begin{array}{c}.06 \\
(.164)\end{array}$ & 1 & & & & & & & & & \\
\hline & News (F) & $\begin{array}{c}.14 \\
(.001)\end{array}$ & $\begin{array}{c}.57 \\
(<.001)\end{array}$ & $\begin{array}{c}.07 \\
(.100)\end{array}$ & $\begin{array}{c}.15 \\
(<.001)\end{array}$ & $\begin{array}{c}.16 \\
(<.001)\end{array}$ & 1 & & & & & & & & \\
\hline & $\begin{array}{l}\text { Searching for } \\
\text { information }(\mathrm{G})\end{array}$ & $\begin{array}{c}.14 \\
(.001)\end{array}$ & $\begin{array}{c}.29 \\
(<.001)\end{array}$ & $\begin{array}{c}.08 \\
(.040)\end{array}$ & $\begin{array}{c}.16 \\
(<.001)\end{array}$ & $\begin{array}{c}.16 \\
(<.001)\end{array}$ & $\begin{array}{c}.43 \\
(<.001)\end{array}$ & 1 & & & & & & & \\
\hline & Web surfing $(\mathrm{H})$ & $\begin{array}{c}-.07 \\
(.101)\end{array}$ & $\begin{array}{c}.25 \\
(<.001)\end{array}$ & $\begin{array}{c}.09 \\
(.030)\end{array}$ & $\begin{array}{c}.12 \\
(.003)\end{array}$ & $\begin{array}{c}.05 \\
(.251)\end{array}$ & $\begin{array}{c}.31 \\
(<.001)\end{array}$ & $\begin{array}{c}.44 \\
(<.001)\end{array}$ & 1 & & & & & & \\
\hline & Games (I) & $\begin{array}{c}.15 \\
(<.001)\end{array}$ & $\begin{array}{c}.07 \\
(.098)\end{array}$ & $\begin{array}{c}.04 \\
(.309)\end{array}$ & $\begin{array}{c}.06 \\
(.177)\end{array}$ & $\begin{array}{c}.20 \\
(<.001)\end{array}$ & $\begin{array}{c}.07 \\
(.070)\end{array}$ & $\begin{array}{l}-.01 \\
(.787)\end{array}$ & $\begin{array}{l}.10 \\
(.018)\end{array}$ & 1 & & & & & \\
\hline & TV/video (J) & $\begin{array}{c}.23 \\
(<.001)\end{array}$ & $\begin{array}{c}.05 \\
(.220)\end{array}$ & $\begin{array}{c}.06 \\
(.152)\end{array}$ & $\begin{array}{c}.11 \\
(.005)\end{array}$ & $\begin{array}{c}.17 \\
(<.001)\end{array}$ & $\begin{array}{c}.19 \\
(<.001)\end{array}$ & $\begin{array}{c}.10 \\
(.015)\end{array}$ & $\begin{array}{l}-.01 \\
(.788)\end{array}$ & $\begin{array}{c}.16 \\
(<.001)\end{array}$ & 1 & & & & \\
\hline & Music (K) & $\begin{array}{c}-.02 \\
(.693)\end{array}$ & $\begin{array}{c}.09 \\
(.024)\end{array}$ & $\begin{array}{c}.04 \\
(.284)\end{array}$ & $\begin{array}{c}-.13 \\
(.002)\end{array}$ & $\begin{array}{c}.17 \\
(<.001)\end{array}$ & $\begin{array}{c}.13 \\
(.002)\end{array}$ & $\begin{array}{c}.13 \\
(.001)\end{array}$ & $\begin{array}{c}.22 \\
(<.001)\end{array}$ & $\begin{array}{c}.26 \\
(<.001)\end{array}$ & $\begin{array}{c}.25 \\
(<.001)\end{array}$ & 1 & & & \\
\hline & Webtoons (L) & $\begin{array}{c}.26 \\
(<.001)\end{array}$ & $\begin{array}{c}.22 \\
(<.001)\end{array}$ & $\begin{array}{c}.14 \\
(.001)\end{array}$ & $\begin{array}{c}.21 \\
(<.001)\end{array}$ & $\begin{array}{c}.21 \\
(<.001)\end{array}$ & $\begin{array}{c}.37 \\
(<.001)\end{array}$ & $\begin{array}{c}.38 \\
(<.001)\end{array}$ & $\begin{array}{c}.35 \\
(<.001)\end{array}$ & $\begin{array}{c}.24 \\
(<.001)\end{array}$ & $\begin{array}{c}.33 \\
(<.001)\end{array}$ & $\begin{array}{c}.31 \\
(<.001)\end{array}$ & 1 & & \\
\hline & Messengers (M) & $\begin{array}{c}.06 \\
(.139)\end{array}$ & $\begin{array}{c}.48 \\
(<.001)\end{array}$ & $\begin{array}{c}.20 \\
(<.001)\end{array}$ & $\begin{array}{c}.11 \\
(.011)\end{array}$ & $\begin{array}{c}-.09 \\
(.030)\end{array}$ & $\begin{array}{c}.36 \\
(<.001)\end{array}$ & $\begin{array}{c}.33 \\
(<.001)\end{array}$ & $\begin{array}{c}.29 \\
(<.001)\end{array}$ & $\begin{array}{c}.09 \\
(.023)\end{array}$ & $\begin{array}{c}.08 \\
(.048)\end{array}$ & $\begin{array}{c}-.01 \\
(.907)\end{array}$ & $\begin{array}{c}.22 \\
(<.001)\end{array}$ & 1 & \\
\hline & SNS (N) & $\begin{array}{c}.00 \\
(.997)\end{array}$ & $\begin{array}{c}.47 \\
(<.001)\end{array}$ & $\begin{array}{c}.18 \\
(<.001)\end{array}$ & $\begin{array}{c}.12 \\
(.004)\end{array}$ & $\begin{array}{c}-.04 \\
(.331)\end{array}$ & $\begin{array}{c}.38 \\
(<.001)\end{array}$ & $\begin{array}{c}.33 \\
(<.001)\end{array}$ & $\begin{array}{c}.32 \\
(<.001)\end{array}$ & $\begin{array}{c}.16 \\
(.158)\end{array}$ & $\begin{array}{c}.13 \\
(.002)\end{array}$ & $\begin{array}{c}.18 \\
(<.001)\end{array}$ & $\begin{array}{c}.25 \\
(<.001)\end{array}$ & $\begin{array}{c}.48 \\
(<.001)\end{array}$ & 1 \\
\hline
\end{tabular}

TV=Television; SNS=Social networking services.

Table 3. Smartphone Use Patterns Associated with More Severe Smartphone Dependence

$(N=595)$

\begin{tabular}{|c|c|c|c|c|}
\hline Variables & Categories & $\beta$ & SE & $p$ \\
\hline Duration of smartphone use & & .01 & .09 & .781 \\
\hline Frequency of smartphone use & & .21 & .00 & $<.001$ \\
\hline Degree of use & $\begin{array}{l}\text { Learning } \\
\text { News } \\
\text { Searching for information } \\
\text { Games } \\
\text { TV/video } \\
\text { Webtoons }\end{array}$ & $\begin{array}{r}.24 \\
-.03 \\
-.04 \\
.00 \\
.10 \\
.08\end{array}$ & $\begin{array}{l}.06 \\
.07 \\
.08 \\
.10 \\
.06 \\
.07\end{array}$ & $\begin{array}{r}<.001 \\
.510 \\
.389 \\
.943 \\
.032 \\
.153\end{array}$ \\
\hline
\end{tabular}

Covariates are sex and age; TV=Television. 
Previous studies reported that the frequent use of smartphones was one of the characteristics of smartphone dependence [17], and it is known to be more associated with dependence than prolonged duration of use [10]. The findings of this study indicate that elementary school students tended to use smartphones very frequently, similarly to dependent smartphone users in other age groups [18]. The frequent use of smartphones provides expedient gratification for the repetitive desire to use smartphone [10]. Therefore, such use patterns could imply that smartphone-dependent elementary school students are under severe conditions of deprivation of self-control over smartphone use.

Games were the most popular type of application for elementary school students with smartphone dependence; however, they were not a significant factor associated with more severe smartphone dependence. This means that regardless of the level of dependence, elementary school students with smartphone dependence tend to play games on their smartphones more often than other applications. Several studies have reported that the use of gaming applications was closely correlated with smartphone dependence [8,10,17], and similar findings have been reported for elementary school students $[8,12,13]$. The purpose of games is generally pleasure and entertainment [8], which would be expected to result in severe smartphone dependence [8]. Dependent smartphone users who play games on their smartphones often spend an extended amount of time doing so, and they tend to play games more frequently in a habitual manner in order to reach their desired goals (a certain level of in-game achievements) [17]. Even more concerning, novel gaming programs are constantly being developed, and they are most easily accessible through smartphones. Therefore, special attention should be paid when children mainly play games on their smartphones. Another finding of this study is that the elementary school students in the potential-risk group, with a lower degree of dependence, tended to use messengers, while the use of TV/ video and learning applications increased significantly as the level of dependence became more severe. Watching TV and videos is a typical way of seeking pleasure and entertainment [17]. This finding indicates that elementary school students who are more heavily dependent on smartphone use tend to use applications geared towards spending time alone in pursuit of entertainment. Compared to smartphone nondependent elementary school students, those with smartphone dependence were found to engage in excessive use of not only gaming applications, but also SNS and messenger applications $[8,12]$, and maintained relationships with their peers mainly through smartphones [11-13]. This indicates that issues tend to arise among smartphone-dependent elementary school students regarding social dynamics with their peers, and these issues may be exacerbated as their smartphone dependence becomes more serious. For elementary school students, developing social relationships with their peers is the most crucial type of social interaction [19]. The premier task for elementary school students is to form a group with rules and values; children form the concept of self from their real-life experiences of relationships with fellow children and learn how to interact with other people within their peer group. They also tend to develop the concepts of acceptance and refusal within their peer group by interacting with their fellow children, and modify their modes of behavior in order to gain acceptance [19]. However, elementary school students with smartphone dependence are deprived of opportunities to learn through hands-on social interactions, and they tend to become more obsessed with their relationship with a smartphone, which provides a solitary form of entertainment, whenever they experience difficulties such as rejection or trials and errors. The American Association of Pediatrics recommends restricting the use time of media for children aged 6 or older and prohibiting media exposure that interferes with or replaces proper sleep, physical activities, and other health-related activities [20]. Hence, parents with elementary school students need to observe their children's smartphone use patterns. Parents need to set ground rules for using smartphones, while closely communicating with their children so that the children can maintain an appropriate balance between time spent on activities with a useful purpose and time spent on recreation and entertainment [21], and they should discipline their children as appropriate to induce them to follow these rules. Parents also need to ensure that their children find other sources of entertainment or pleasure besides smartphone use. Parents' care and mediation may lead to changes in children's behavior [11-13]. Meanwhile, the use of learning applications also increased with increasingly severe dependence. This tendency should be seen in light of elementary school students' use patterns of learning applications. In general, today's smartphone applications employ a variety of attractive and entertaining elements, and learning applications for children are no exception. Learning applications for children are often built in the form of games that children like, so that they can excite more interest in their target consumers. Most parents tend to allow children to use such applications for learning [22]. Hence, it is likely that elementary school students with smartphone dependence are exposed to games built into learning applications without limitations, since those games may be perceived as learning activities. Thus, in practice, elementary school students may not use learning applications to acquire and understand educational materials [7]. If smartphones are utilized effectively in learning activities, the use of learning applications either would show no 
correlation with smartphone dependence or would be associated with lower levels of smartphone dependence, as previous studies have suggested [8]. Hence, it is necessary to ensure that children use smartphones properly by monitoring the content of applications and their use patterns closely, even when they are using a smartphone for educational purposes.

This study has a few limitations. First, it was not possible to consider additional variables that may be correlated with smartphone dependence as a secondary data source was used. Secondly, since this study analyzed findings from a descriptive cross-sectional survey, there are limitations in the interpretation of factors found to be correlated with smartphone dependence.

\section{CONCLUSION}

The findings of this study identified factors that we need to consider when guiding and educating elementary school students on proper smartphone use. The children with smartphone dependence mostly used gaming applications, regardless of the level of dependence. As the level of dependence became more severe, the children were inclined to use smartphones more frequently and to employ use patterns reflecting their tendency to seek out pleasure and entertainment. These use patterns may cause issues in peer relationships, which are a crucial developmental task for children of this age group. Therefore, parents with elementary school students need to understand their children's smartphone use patterns in detail, should guide them on the proper use of smartphones, and should apply consistent discipline after agreeing upon rules on smartphone use. In addition to education on healthy smartphone habits, parents should encourage physical activity among elementary school students and provide them with a variety of opportunities to form and maintain peer relationships in real life.

\section{Conflict of interest}

No existing or potential conflict of interest relevant to this article was reported.

\section{REFERENCES}

1. Choi DJ, Kim YS, Um NR, Kim HS. The survey on smartphone overdependence [Internet]. Annual Report. Seoul: Ministry of Science and ICT, National Information Society Agency; 2018 December. Report No.: NIA VI-RSE-C-18060. Available from:

https://www.nia.or.kr/site/nia_kor/ex/bbs/View.do?cbIdx=65 $914 \& b c I d x=20876 \&$ parentSeq $=20876$

2. Panova T, Carbonell X. Is smartphone addiction really an addic- tion? Journal of Behavior Addiction. 2018;7(2):252-259.

https://doi.org/10.1556/2006.7.2018.49

3. Choi DJ, Kim YS, Um NR, Kim HS. The survey on smartphone overdependence [Internet]. Annual Report. Seoul: Ministry of Science and ICT, National Information Society Agency; 2017 December. Report No.: NIA V-RER-C-17042. Available from:

https://www.nia.or.kr/site/nia_kor/ex/bbs/View.do?cbIdx=65 914\&bcIdx=19592\&parentSeq=19592

4. Kim MY, Kang GS, Kwon YJ, Kwon IS, Kim SH, Kim JS, et al. Child health promotion nursing. 1st ed. Paju: Soomoonsa; 2018. p. 215282.

5. Vanderloo LM. Screen-viewing among preschoolers in childcare: A systematic review. BMC Pediatrics. 2014;14:205.

https://doi.org/10.1186/1471-2431-14-205

6. Sohn S, Rees P, Wildridge B, Kalk NJ, Carter B. Prevalence of problematic smartphone usage and associated mental health outcomes amongst children and young people: A systematic review, meta-analysis and GRADE of the evidence. BMC Psychiatry. 2019;19:356. https://doi.org/10.1186/s12888-019-2350-x

7. Sarwar M, Soomro TR. Impact of smartphone's on society. European Journal of Scientific Research. 2013;98(2):216-226.

8. Jeong S, Kim H, Yum J, Hwang Y. What type of content are smartphone users addicted to?: SNS vs. games. Computers in Human Behavior. 2016;54:10-17.

https://doi.org/10.1016/j.chb.2015.07.035

9. Lee H, Kim JW, Choi TY. Risk factors for smartphone addiction in Korean adolescents: Smartphone use patterns. Journal of Korean Medical Science. 2017;32(10):1674-1679. https://doi.org/10.3346/jkms.2017.32.10.1674

10. Liu CH, Lin SH, Pan YC, Lin YH. Smartphone gaming and frequent use pattern associated with smartphone addiction. Medicine. 2016;95(28):e4068. https://doi.org/10.1097/MD.0000000000004068

11. Lee E, Kim H. Gender differences in smartphone addiction behaviors associated with parent-child bonding, parent-child communication, and parental mediation among Korean elementary school students. Journal of Addictions Nursing. 2018;29(4):244-254. https://doi.org/10.1097/JAN.0000000000000254

12. Chang FC, Chiu CH, Chen PH, Chiang JT, Miao NF, Chuang HY, et al. Children's use of mobile devices, smartphone addiction and parental mediation in Taiwan. Computers in Human Behavior. 2019;93:25-32. https://doi.org/10.1016/j.chb.2018.11.048

13. Koo HY, Kim EJ. Cell phone addiction in school-age children and related factors. Child Health Nursing Research. 2015;21(1):55-63. https://doi.org/10.4094/chnr.2015.21.1.55

14. National Information Society Agency. 2016 Digital culture forum policy research report [Internet]. Research Report. Daegu: National Information Society Agency; 2016 December. Report No.: NIA V-PER-B-16007. Available from:

https://www.nia.or.kr/site/nia_kor/ex/bbs/View.do?cbIdx=39 
$485 \& b c I d x=18317 \&$ parentSeq $=18317$

15. Choi J, Rho MJ, Kim Y, Yook IH, Yu H, Kim DJ, et al. Smartphone dependence classification using tensor factorization. PLoS ONE. 2017;12(9):e0177629.

https://doi.org/10.1371/journal.pone.0177629

16. Ministry of Science and ICT. Statistics micro-data service [Internet]. Chungcheongbuk-do: IT Statistics of Korea; 2017 [cited 2018 October 03]. Available from: http://www.itstat.go.kr/pub/applyMicro.it

17. Fischer-Grote L, Kothgassner OD, Felnhofer A. Risk factors for problematic smartphone use in children and adolescents: A review of existing literature. Neuropsychiatrie. 2019;33(4):179-190. https://doi.org/10.1007/s40211-019-00319-8

18. Park JH. Recognition of smartphone dependence of adolescents at risk of smartphone addiction. Journal of the Korean Data Analysis Society. 2019;21(4):2095-2105.
19. Ricci S, Carman S, Kyle T. Study guide for maternity and pediatric nursing. 3rd ed. Philadelphia: Lippincott Williams and Wilkins; 2016. p. 1049-1075.

20. American Association of Pediatrics. American Academy of Pediatrics announces new recommendations for children's media use [Internet]. USA: American Association of Pediatrics; 2016 [cited 2019 August 10]. Available from:

https://www.aap.org/en-us/about-the-aap/aap-press-room/Pa ges/American-Academy-of-Pediatrics-Announces-New-Recom mendations-for-Childrens-Media-Use.aspx

21. Zimmerle JC. Limiting technoference: Healthy screen time habits for new parents. International Journal of Childbirth Education. 2019;34(2):54-59.

22. Genc Z. Parents' perceptions about the mobile technology use of preschool aged children. Procedia-Social and Behavioral Sciences. 2014;146:55-60. https://doi.org/10.1016/j.sbspro.2014.08.086 